\title{
RESCATANDO LOS PRODUCTOS Y LA SAZÓN DE NUESTROS PUEBLOS: CRÓNICA DEL ACOMPAÑAMIENTO A LAS "MAESTRAS DE LA GASTRONOMÍA SANTANDEREANA"
}

Semillero de investigación en Gastronomía y Alta Cocina. Universidad Autónoma de Bucaramanga. Julián Francisco Martínez Caballero, Gabriela Blanco Díaz,Mónica Nathalia Anaya Román, Paul David Cañas Carvajal, Leonardo Augusto Gelvez, Jorge Nicolás Salcedo Rivero, Deybee Nicolás Osorio Lesmes, Diego Fernando Capacho, Schneider Acuña Maldonado y Manuel Ernesto Acebedo Martínez (profesor orientador) Correo:jmartinez522@unab.edu.co macebedo353@unab.edu.co 


\section{RESCATANDO LOS PRODUCTOS Y LA SAZON DE NUESTROS PUEBLOS: CRONICA DEL ACOMPAÑAMIENTO A LAS "MAESTRAS DE LA GASTRONOMIA SANTANDEREANA"}

Como parte del interés colectivo de los estudiantes del programa profesional en Gastronomía y Alta Cocina por aquellas cuestiones que atañen al amplio mundo de los bienes de interés cultural-BIC y en particular aquellos que hacen parte del acervo cultural gastronómico de Santander, nace la idea, dentro de los intereses del semillero de investigación del programa académico en mención, por buscar las fuentes de conocimiento que actualmente portan el saber culinario del departamento. Fue de manera oportuna que la organización Obusinga se acercó a nosotros, los estudiantes de gastronomía, para que hiciéramos parte de un proceso que pretendía desarrollar un proceso de salvaguardia del conocimiento de las portadoras de saberes ancestrales gastronómicos de Santander.

Al establecer un canal de diálogo abierto con los miembros de Obusinga se pudieron consensuar y concertar ciertas cuestiones respecto a las modalidades de intervención con las distintas comunidades con las que se pretendía abordar el proceso de salvaguardia. Se tuvo así que los municipios de Bolívar, Vélez, San Vicente de Chucurí, Barrancabermeja y Puerto Wilches fueron los seleccionados para este primer episodio de lo que se esperan sea una entrega por cada municipio de Santander. De igual manera, al ser Obusinga quien, como parte de un equipo transdisciplinar (ya que contamos con la participación de estudiantes de gastronomía, profesionales de la medicina y otros desde las ciencias sociales) contaba con un presupuesto para hacer investigaciones "in situ" fue esta organización la encargada de desarrollar un proceso de selección de las Maestras.
Toda esta etapa del proceso fue documentada y analizada en diversos textos no editados que hacen parte del fondo documental acumulado de Obusinga, los cuales fueron puestos a disposición de los estudiantes pero su divulgación es restringida, por lo tanto, se citan solo ciertos apartes de los mismos. Respecto al proceso de selección, se puede entender la política y filosofía del mismo a través de la siguiente cita:

"La primera fase del proyecto "Maestras de la gastronomía tradicional", es la selección de las participantes. Se trata de identificar las cocineras tradicionales que oficiarán como maestras culinarias del proceso formativo y, a través de ellas, convocar $e$ incorporar a los discípulos locales (jóvenes apasionados por la cocina). El propósito del proceso radica en favorecer la transmisión del saber gastronómico tradicional por medio de la identificación de las personas portadoras de la cultura alimentaria tradicional y de jóvenes de las mismas localidades que se vayan formando en las bases de la gastronomía tradicional." De igual manera, se hace énfasis en lo crucial que es el proceso de escrutinio, ante lo cual se señala que "Desde un principio se tuvo previsto que las maestras fueran elegidaspor su conocimiento empírico de la cocina tradicional de sus municipios $e$ identificadas por la trayectoria localreconocida por los lugareños. Por estos motivos la realización del proceso de identificación de las maestras culinarias se pensó por medio de una exploración etnográfica recurriendo al prestigio y reconocimiento que tengan por parte de la población." Finalmente, dentro 
de las conclusiones se menciona que "Definitivamente, centrar el proceso de selección de las maestras de la gastronomía tradicional en la legitimidad de quienes las postulan fue un acierto." Agregando como justificación de su acierto que: "[...] si consideramos que el patrimonio cultural gastronómico le pertenece al conjunto de la comunidad y no solo a quién cocina, definitivamente, dicho patrimonio procede de la relación entre quien prepara y quien consume, entre cocinero y comensal [...] De esta manera, el patrimonio gastronómico es producto de una estética construida entre el cocinero o cocinera y sus comensales, entre el artista y su público."

Una vez tuvimos claro esto, el proceso de inserción se dio de manera paulatina y sistemática, recurriendo primero al acompañamiento de un historiador docente del programa y luego a la selección de los estudiantes que desde el grupo haríamos las visitas a cada uno de los municipios seleccionados.

En este proyecto de identificación, rescate y reconocimiento de las "Maestras de la Cocina Tradicional" en Santander se busca la salvaguardia y el posicionamiento del trabajo de estas mujeres como hito gastronómico de Santander. SI bien el proyecto "Maestras de la Cocina Tradicional", en su primera fase, se desarrolló en los municipios de Bolívar, Vélez, San Vicente de Chucurí, Barrancabermeja y Puerto Wilches, fue principalmente en el primero en mención donde tuvimos la gran oportunidad de conocer y compartir con las señoras ( $Y$ de aquí en adelante se nombrarán a ellas y las demás portadoras de saber gastronómico como Maestras) Sara María Chacón y Transito Vargas, hijas de este maravilloso pueblo rodeado de montañas y de personas tradicionalmente amables.

Dentro de este proceso se pretendió entrar a la intimidad de sus cocinas y de sus secretos culinarios que han sido transmitidos desde el pasado, de generación en generación, por vía oral y por el proceso de enseñanza dentro de las labores domésticas cotidianas; sin embargo, como las mismas Maestras dicen: "las chinas de hoy en día, solo piensan en salir del pueblo y que las mantengan". En este punto entramos nosotros como estudiantes del programa profesional en Gastronomía y Alta Cocina para manifestarles a ellas nuestro interés por esta loable y en ocasiones desconocida labor.

La metodología empleada para abordar este proyecto fue heredada de las clases dentro del programa académico de Gastronomía y Alta Cocina que nos forman a los estudiantes en reconocimiento $y$ salvaguardia del patrimonio cultural gastronómico. En ese sentido, de la cátedra de Cultura Material e Inmaterial tomamos las nociones pertinentes a patrimonio, bienes de interés cultural-BIC y salvaguardia, todos ellos, derivados de la normatividad nacional en sincronía con los postulados rectores de la UNESCO; por su parte, de la cátedra de Antropología Cultural tomamos las pautas enseñadas sobre método etnográfico en las que se expone en detalle los requerimientos para hacer una intervención desde las pautas de la observación participante, llevando constante registro del proceso y procurando generar en las Maestras una sensación de confianza y confortabilidad para que, no solo ejecuten con gran destreza sus preparaciones, sino que nos enriquezcan con aquellos detalles culinarios y anécdotas de vida que son la esencia de la cocina tradicional.

Así que, como resultado del proceso de acompañamiento y observación, y en palabras de las Maestras de la cocina tradicional de Santander 
"vengan, nos tomamos un cafecito y charlamos".

En esta ocasión las que tienen que hablar son las Maestras, nosotros nos limitamos a observar, escuchándolas y tomando nota de lo que más podamos. EN el municipio de Bolívar, la señora Transito nos sorprende con una mazamorra de maíz oriunda de Bolívar y preparada tal cual como se lo enseñara su señora madre, con productos autóctonos de la región; igualmente la señora Sara María prepara un sancocho de Bolívar que le fue enseñado, desde que era pequeña, por su señora madre.

Lo que se puede destacar es que estas dos Maestras tienen formas muy distintas de cocinar, por ejemplo doña Tránsito nos comenta que ella lo primero que hace es poner a hervir agua para que sea más rápido la preparación, se puede ver que ella siempre está pensando en el tiempo ya que tiene otros oficios en su casa como lo es el cuidado de sus nietos y los que haceres del hogar; mientras que Sara María lo primero que hace es alistar su materia prima (lo que en culinaria se conoce como "mise en place", pero ella dice no conocer ese término), ella lo primero que hace es un guiso en el cual todos los productos que le componen son cortados en la mano y manifiesta ella que la tablano es necesaria, inmediatamente agrega mantequilla y el guiso a una olla previamente puesta en el fogón, donde lo sofríe. La cocina se inunda de aromas muy fuertes y fáciles de reconocer como el del ajo, la cebolla, la rama de apio y la zanahoria, después agrega el agua con la carne (en este caso costillas de res), con un poco de sal.

Es pertinente aclarar que estas Maestras manifiestan que no suelen ausentarse por mucho tiempo del municipio, lo cual evidencia la importancia de conocerle con el fin de averiguar que de este conocimiento gastronómico puede ser netamente producto de las vicisitudes geográficas y culturales de Bolívar y sus veredas aledañas. Ya habiendo aclarado esto, la Maestra Sara María hace un atado con el tallo de las guacas, cilantro, rama de apio y perejil, luego lo amarra con una rama de cebolla larga. llama la atención ya que esta técnica se conoce como "buquet garni" y al preguntarle el porqué de ese atado ella nos dice: "mi mamá siempre lo hacía para dar sabor a la preparación", seguido a esto pone una tapa y se sienta a tomarse un "tintíco" (qué es un café-negro servido en un pocillo pequeño); mientras tanto la señora Transito pone en su olla el agua que ya previamente tenía aparte hirviendo y empieza a agregarla poco a poco, dice ella, para poder medir la cantidad. En la olla donde ella va a preparar su mazamorra pone la carne picada en trozos pequeños con ajo y cebolla larga sin agregarle más, aparte, ella trae de su casa el maíz y nos explica el proceso que hizo para pelarlo.

Los artefactos de madera son indispensables para estas Maestras de la cocina. Para ellas no hay mejor cucharona que una de palo, ésta puede ser de guayabo, naranjo o de limón; actualmente en las cocinas están prohibidos los utensilios de madera o palo ya que estos permiten la proliferación de hongos y bacterias debido a su humedad que fácilmente pueden ser transmitido a los comensales causando irritaciones estomacales y algún tipo de daño gástrico, sin embargo, este tabú en las cocinas tradicionales no se tiene presente, pues el uso de utensilios de madera es ancestral y tradicional, constituyéndose así como parte del acervo cultural gastronómico de la región. Durante la preparación las Maestras manejan una higiene óptima. Al probar (los alimentos en proceso de cocción) ellas lavan su cuchara, igualmente a la hora de manipular los productos manejan un lavado previo y durante la preparación. 
Después de escuchar diversas anécdotas sobre la vida de estas dos Maestras llega el momento de dar los toques finales de sus platos, a saber: doña Tránsito al agregar su maíz no permite que nadie más "le meta la mano" (como ella exclama), ya que la pueden "cortar"; en ese momento la cocina era una sinfonía compuesta por innumerables aromas que hacen la composición perfecta. Sirve a la mesa con cilantro recién picado, mientras doña Sara María hace un picado de cebolla larga, cilantro y perejil y lo coloca en la mitad de la mesa. El sancocho estaba en su punto: se podía identificar cada producto que tenía ya que ella empezó a cocinar los productos más duros hasta los más blanditos sin deshacerlos. Es necesario señalar que ese toque al momento de agregarle el "picado de yerbas y verduras" ya mencionado le confiere un gusto especial a este plato donde el aroma y el sabor se fortalecen llegando a todos los sentidos presentes a la hora de comer.

Para la siguiente visita se realizaron dos preparaciones, la primera fue un piquete de carne de res realizado por la Maestra Transito que es un plato oriundo de Bolívar y la segunda preparación fue un tamal por parte de la Maestra Sara María que nos comentaba que era el único tamal que se podría ver preparado de esa forma debido a que era una receta exclusivamente de la familia Chacón. Antes de empezar con el segundo taller la Sra. Sara María prepara un "tinto" al estilo de su " señora madre" que consistía en preparar un "melao" a base de panela para posteriormente agregárselo al agua hirviendo con el que se iba a realizar el "tinto". Después de haber compartido el "tinto" nos disponemos a realizar la primera preparación del piquete de carne de res con la Sra. Transito quien previamente había solicitado los siguientes productos de la región: Papa, yuca, chonque, malanga, guatilla verde, bore amarillo, pierna de res y apio; Lo primero que se hace, es cocinar la carne, en estufa a gas por aproximadamente 30 min, aparte, se corta cierta variedad de tubérculos mencionados anteriormente y se cocinan al vapor. Según lo dicho por una de nuestras maestras es que algunos de los productos usados en esta preparación son de esta región y que son un poco difíciles de encontrar además nos comentó que antiguamente este era uno de los platillos que se les llevaba a los jornaleros. Mientras la Sra. Transito conversaba con sus aprendices sobre la historia de su preparación, la Sra. Sara María estaba con su discípulo realizando el "mise en place" de los productos para sus tamales, que eran: Alverja, zanahoria, cebolla larga, cebolla cabezona, tocino de cerdo, costilla, gallina, arroz y hojas de plátano; para esta segunda preparación Iniciamos cortando la zanahoria y lavamos la alverja, cortamos los dos tipos de cebollas y salteamos con un poco de grasa de cerdo (tocino o panceta) vamos mezclando y dejamos que se cocine por aproximadamente $8 \mathrm{~min}$. Después de esto se le agregan dos tazas de agua y una de arroz (esto va dependiendo de la cantidad de arroz a utilizar). Se deja cocinar el arroz junto con las verduras. Después de esto retiramos del fuego y agregamos cantidades de aproximadamente 150 a 250 gramos de esta preparación sobre hojas de plátano limpias y envolvemos, luego llevamos los tamales a cocinar a vapor por 30 a $40 \mathrm{~min}$.

En la primera visita realizada en la ciudad de Barrancabermeja compartimos momentos de integración y escuchamos las anécdotas de la niñez de las señoras Claribel Simanca (conocida como "Bolliri") y Rosalía Reyes, después de esta integración las Maestras se dedicaron a enseñarles las técnicas a sus aprendices con el fin de que ellos en un futuro puedan seguir con el legado; de igual manera las personas que hacíamos el papel de observadores aprendimos algunos trucos esenciales a la hora de elaborar un plato, de igual 
manera aprendimos sobre los tipos de peces.

El día 12 de agosto se realizó la siguiente visita la cual denominamos como "jornada de innovación y tradición" debido a los platos presentados por las dos maestras, en esta ocasión la Sra. Rosalía nos presentó un plato innovador, una deliciosa picada de pescado, un plato poco común debido a que su mamá fue la que lo invento para presentarlo en el festival del pescado. La picada consistía de trozos de (doncella, blanquillo, boca chico, cachama) los cuales se cubrían con una capa de harina y finas hierbas, lo que le resaltaba el sabor, por otra parte la señora Claribel (Bollirri) nos mostró la tradicional forma de hacer bollos de coco y el auténtico bollo limpio, se combinaron las dos preparaciones dando como resultado un espectacular plato lleno de innovación y tradición.

En el siguiente encuentro el turno fue para los aprendices quienes eligieron dos platos típicos de la región y de la ribera del rio magdalena, en el caso de la Sra. Claribel, sus aprendiz preparó una carne molida cocinada en guiso criollo, arroz y una ensalada de papa y huevo; en el caso de la Sra. Rosalía sus aprendicesoptaron por un plato mástradicional, viuda de pescado cocinada con hoja de bijao, como acompañamiento yuca y plátano extraídas de las orillas del rio. Al finalizar la degustación se socializó con las cocineras, las cuales quedaron totalmente satisfechas por la labor que habían realizado sus aprendices.

Esta ha sido una experiencia única donde aprendimos sobre cocina tradicional y autóctona santandereana a través de las preparaciones y las anécdotas de las Maestras. Podemos mejorar aspectos referentes a la manipulación de los alimentos pero a la preparación como tal sería impensable (i!) agregarle o quitarle algo; de esta manera, depende de los gastrónomos y entusiastas de la cocina que estas preparaciones perduren y trasciendan como platos típicos-tradicionales de Santander.

Citar este artículo como: Acebedo, M., et al. (2017) "Rescatando los productos y la sazón de nuestros pueblos: crónica del acompañamiento a las 'maestras de la gastronomía santandereana'". En: Revista La Tercera Orilla (19). Bucaramanga: Universidad Autónoma de Bucaramanga. 